\title{
Searching for allelopathic effects of submerged macrophytes on phytoplankton-state of the art and open questions
}

\author{
Elisabeth M. Gross · Sabine Hilt (nee Körner) • \\ Paola Lombardo - Gabi Mulderij
}

\begin{abstract}
Allelopathy, here defined as biochemical interactions between aquatic primary producers, has always been intriguing as a process explaining the dominance of certain plant or algal species over others. Negative chemical interference has been invoked as one of the steering mechanisms behind mutual dominance of either submerged macrophytes or phytoplankton in shallow eutrophic lakes. Yet, despite much effort, convincing evidence for allelopathic interactions in situ is still missing. Also, laboratory approaches often lack reality. Inspired by a series of talks at the Shallow Lakes 2005 meeting in Dalfsen, the Netherlands, we argue that there is
\end{abstract}

Guest editors: R. D. Gulati, E. Lammens, N. De Pauw \& E. Van Donk

Shallow lakes in a changing world

\section{E. M. Gross $(\bowtie)$}

Limnological Institute, Biology, University of

Konstanz, P.O. Box 5560 M659, 78457 Konstanz,

Germany

e-mail: Elisabeth.Gross@uni-konstanz.de

S. Hilt (nee Körner)

Leibniz-Institute of Freshwater Ecology and Inland

Fisheries, Müggelseedamm 301, 12587 Berlin,

Germany

\section{P. Lombardo}

Department of Genetics and Molecular Biology -

Ecology Area, La Sapienza State University of Rome, via dei Sardi 70, 00185 Rome, Italy circumstantial but strong evidence that allelopathic interference between submerged macrophytes and phytoplankton may indeed exist in aquatic ecosystems despite the problems associated with research in this field. We first discuss experimental approaches combining laboratory and field studies, based on examples presented at this meeting. We then discuss the impact of nutrient status of both producing and target organism and biotic factors such as herbivory or pathogens that might affect allelopathy. Further topics are the potential seasonality of effects and the species-specificity of certain allelochemicals. We conclude with some thoughts why a final

\section{G. Mulderij}

Netherlands Institute of Ecology, Centre for Limnology, Rijksstraatweg 6, 3631 AC Nieuwersluis, The Netherlands

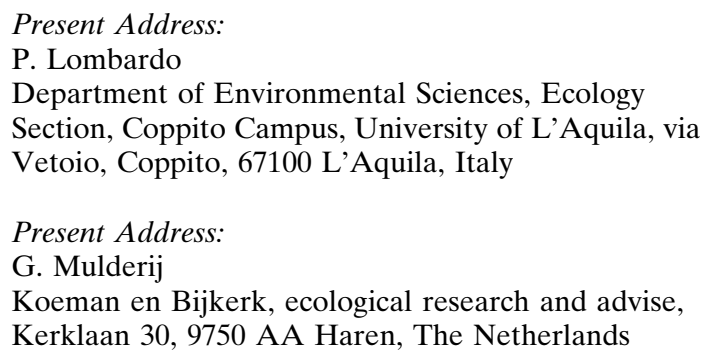

Present Address:

G. Mulderij

Koeman en Bijkerk, ecological research and advise, Kerklaan 30, 9750 AA Haren, The Netherlands 
proof for allelopathy in situ might remain difficult or even inaccessible in some cases, and why we nevertheless should not abandon this idea.

Keywords Allelochemical interaction . Algicidal activity - Chemical interference . Culture filtrate . Exudation

\section{Introduction}

Even before the Vienna botanist Hans Molisch coined the term allelopathy to describe biochemical interactions among plants and between plants and microorganisms (Molisch, 1937), some studies reported negative effects of one primary producer on another not related to resource competition (Harder, 1917; Akehurst, 1931), and multiple studies followed (e.g., Pratt et al., 1944; Keating, 1977). Although by its original definition, stimulatory and inhibitory allelopathic effects might occur, most studies report negative interactions. Some early prominent reports on detrimental chemical effects of aquatic plants on microalgae are the studies by Hasler \& Jones (1949), Fitzgerald (1969), Kogan \& Chinnova (1972). Further information is compiled in the reviews by Gopal \& Goel (1993) and Gross (2003a).

We now have ample evidence that low phytoplankton and epiphyte densities in shallow eutrophic lakes might be the result of complex abiotic and biotic feedback mechanisms, and allelopathy is considered as one alternative mechanism (Scheffer et al., 1993). The importance of pelagic and benthic trophic interactions, as well as physical and chemical conditions such as resuspension or sedimentation, shading or increased carbonate (and phosphate) precipitation have all been investigated at a wide range of spatial and temporal scales, with laboratory, mesocosm and field experiments.

In contrast, proving evidence for allelopathy still remains difficult. According to Willis (1985), six prerequisites have to be met to unequivocally show the occurrence of allelopathy: (1) a pattern of inhibition of target plant(s) or alga(e), (2) allelopathical compound(s) produced by donor plants, (3) the release of these compounds by the producing plant, (4) their transport and/or accumulation in the environment, (5) the uptake by the target organism(s) and (6) the inhibition cannot be explained solely by other physical or biotic factors, especially herbivory and competition. Consequently, experimental approaches on aquatic allelopathy need to address all these aspects.

Studies investigating macrophyte-phytoplankton interactions in shallow, eutrophic lakes have suggested allelopathy as a (co-)factor in explaining plant influence, up to dominance, over phytoplankton at high (i.e., non-limiting) nutrient levels, at least when known allelopathic plant species and/or sensitive phytoplankton species are involved (Phillips et al., 1978; Körner \& Nicklisch, 2002; van Donk \& van de Bund, 2002). Other studies cast doubts on the natural strength, or even the existence of in situ allelopathic interference among primary producers (Forsberg et al., 1990). An understanding of the occurrence, strength, and mode(s) of action of allelopathy in natural situations may therefore result in a major contribution to the understanding and management of eutrophic, shallow lakes. Though allelopathic interactions may exist between all types of primary producers, we specifically focus on plant allelopathy on phytoplankton, as this aspect has the highest applicability to shallow lake ecology.

\section{Experimental approaches, possible insights and inherent problems}

The following section will present frequently used methods to address allelopathy between plants and algae in aquatic systems. While any one method alone cannot be used as proof of allelopathic effects in situ, a combination of those methods might present insight into the strength of allelopathic interactions, the mechanisms involved and explain the variability of responses.

Plant homogenates or extracts

Some authors use plant homogenates or extracts to test for allelopathy. Fresh or dried macrophytes might be homogenated with water, incubated for a certain period, filtered and then the 
filtrate is added to target organisms. Controls receive only water or nothing.

Water is assumed to be the most natural solvent since the plants live in water and have no well-developed cuticle, thus should leach active compounds into the water. Elakovich and colleagues (Elakovich \& Wooten, 1989, 1995; Wooten \& Elakovich, 1991) used fresh macrophytes homogenised with water and the filtrate was then used in bioassays against lettuce seedlings and duckweed. Besides the problems mentioned below when using water as solvent, the utilised target species did not allow ecologically important extrapolations. Problems when using water might arise from osmotic changes caused by the addition of fresh tissue homogenates, including e.g., sugars. If heterotrophic bacteria are present in the target organism culture, they might use these substrates and probably also the inhibitory compounds as co-substrates.

Gross (1999) argued that moderately lipophilic solvents such as methanol, ethanol and acetone or mixtures of those solvents with water are also appropriate to extract more lipophilic compounds that might be transferred by direct cell-cell contact or transported via micelles or aggregates. Using concentrated solvent extracts avoids some of the above mentioned problems. Extracts might be separated further by liquid-liquid or solid phase extraction to distinguish whether hydrophilic or lipophilic compounds are active. Further separation by chromatography (TLC - thin layer chromatography or HPLC - high performance liquid chromatography) guided by bioassays may ultimately lead to the identification of active compounds and their mode(s) of action (Gross et al., 1996; Leu et al., 2002).

Extract-based methods offer the chance to compare the allelopathic potential of different macrophyte species or seasonal differences in one species in a standardised way. The direct application of extracts also enables comparison of the response of nutrient limited and non-limited phytoplankton in order to test whether additional stress of target organisms results in a higher sensitivity against allelopathic substances (Reigosa et al., 1999). Additionally, the producing plants can be cultivated under different nutrient and light conditions to study the impact of resource availability on the production of allelopathic compounds (Gross, 2003b).

Bioassay-directed extractions of Ceratophyllum demersum, Elodea spp., Myriophyllum spp., Najas marina and Stratiotes aloides with different solvents and solvent mixtures (water, methanol, and acetone; pure or mixed with water) often revealed the highest activity against cyanobacteria when solvents with intermediate lipophilic properties were used, e.g., $50 \%(\mathrm{v} / \mathrm{v})$ acetone or $70 \%$ (v/v) methanol in water (Gross et al., 1996, 2003; Erhard \& Gross, 2006; Mulderij et al., 2007). Under these conditions both hydrophilic and moderately lipophilic compounds can be extracted from the plant tissue. This method will result in compounds that in general have a low molecular weight, are fairly water-soluble, and can bind to and/or pass through cell membranes. Further fractionation and separation of extracts by solid phase extraction (SPE) and HPLC can ultimately lead to the bioassay-guided isolation of the active compound(s). These compounds can then also be tracked in culture filtrate or extracts from culture filtrates.

Experiments conducted with extracts certainly give no convincing ecological proof for allelopathic interactions. The inherent difficulties to extract active compounds from a complex matrix of organic and inorganic compounds in the water, however, do not allow the easy identification of released active compounds. Since all exuded active compounds, or their precursors, should be present in much higher concentrations in the plant tissue, working with extracts and a bioassaydirected fractionation using realistic concentrations (i.e., comparable to plant biomass per volume in situ) might provide information about active compounds, and facilitate their structure elucidation. This in turn may facilitate the evaluation of the mode of action (for discussion see Gross, 1999, 2003a). Such studies should only be presented accompanied with experiments using culture filtrate (exudate) from the active macrophytes.

\section{Coexistence experiments}

Comparing growth of co-cultivated plants and/or algae to growth in single-species controls is a 
classical set-up to test for reciprocal interactions. Especially when varying densities of both species are applied, the combined results provide information on positive or negative interactions, facilitation or inhibition. Such experiments have been widely applied in plant ecology as "De Wit replacement series" (Gurevitch et al., 2002), and have also been used to study macrophyte-macrophyte interactions (Agami \& Waisel, 1985). Batch cultures require defined experimental conditions of density and nutrient availability. In order to study the shading effect of coexisting species, either plastic structures resembling macrophytes placed into the growth vessels or nylon stockings mantled around the growth vessels can be used (Körner \& Nicklisch, 2002; Erhard \& Gross, 2006).

Coexistence experiments per se do not provide evidence-either direct or circumstantial-that allelopathy occurs. However, while coexistence experiments quantify the occurrence and strength of competitive-like interspecific interactions, parallel experiments with extracts (or filtrates) may shed light on the possible involvement of allelopathy.

Allelopathy has been invoked as a (co-)factor for changes in algal biomass or assemblage composition when target algae grown in the presence of macrophytes exhibited patterns different from similar cultures grown in the absence of macrophytes (Jasser, 1995; Nakai et al., 1999; Lombardo, Mjelde, Källqvist \& Brettum, unpublished). Similar methods have been adopted for algal-algal (Sukenik et al., 2002) and plant-plant interactions (Elakovich \& Wooten, 1995; Vance \& Francko, 1997).

Though coexistence studies provide a direct evaluation of donor-target species interactions, allelopathy sensu strictu is difficult to isolate as a mechanism behind the observed patterns. Other factors such as presence of other organisms in non-axenic cultures, or competition for resources between coexisting species, may be involved, thus potentially confounding the results.

Only few studies describe the use of axenic macrophytes (e.g., Pringsheim \& Pringsheim, 1962; Forsberg, 1965; Wetzel \& McGregor, 1968; Ervin \& Wetzel, 2000). Although axenic plants represent an artificial system, they can serve as controls that can then be compared to nonaxenic plants. The use of axenic cultures for example enables the investigation of exudates (culture filtrates) that have not been subjected to microbial breakdown. Axenic cultures of Myriophyllum spicatum (surface-sterilised plants) have been established to investigate allelopathic interactions without interference of epiphytic bacteria, cyanobacteria and algae (Gross et al., 1996). Both light and nitrogen availability influenced the content and exudation of allelopathic polyphenols in axenic $M$. spicatum (Gross, 2003b).

Possible competition for light in coexistence experiments may be minimised by using sufficiently small aquaria that can be uniformly permeated by light or by using plastic plants in controls. Potential competition for nutrients may be a thornier issue, as both donor and target species may be actively absorbing, metabolising, and leaking nutrients during experiments. Knowledge about nutrient dynamics in coexistence experiments, coupled with direct measurements of potentially allelopathic compounds (e.g., extracts experiments), may greatly assist in the search for evidence of allelopathy. Though many studies report nutrient concentrations deliberately set at non-limiting levels to exclude competition for nutrients as a factor in donor-target species interactions (e.g., Nakai et al., 1999), coexistence investigations seldom address this issue directly.

Nutrient mediation, whether negatively affecting target species through competition or counteracting inhibition by allelopathy, depending on the physiological status donor and/or target species, cannot be excluded with certainty even at clearly non-limiting nutrient concentrations (Sukenik et al., 2002). Though plants may not be a nutrient (especially phosphorus) sink in the medium- or long-term (weeks to months: Lombardo \& Cooke, 2003), net foliar uptake in the short term (days), at which allelopathy experiments are often performed, may be quite high (Pelton et al., 1998; Lombardo \& Cooke, 2003). Though including nutrient determinations in coexistence experiments may not reveal competition for nutrients as a (co-)factor involved in investigations targeting allelopathy, it 
nonetheless offers some insight when gathering different pieces of evidence in multiple-approach, comprehensive allelopathy investigations.

Even more difficult is the determination of micronutrient availability. Micronutrients such as vitamins, required by some algae and cyanobacteria, including some species commonly used in bioassays (Wetzel, 2001), have never been addressed in allelopathy studies. The involvement of low-weight dissolved organic matter (DOM), continuously leaked by living plants in the surrounding medium (Søndergaard, 1981), also remains little explored. Multiple-approach allelopathy investigations that address at least some of these issues may provide useful insight in the mechanisms behind macrophyte-phytoplankton interactions.

\section{Dialysis bag experiments}

Dialysis bag experiments may be seen as a type of coexistence experiments in which organisms are physically separated by dialysis membranes that allow free movement of low molecular weight compounds. Advantages of this method are the possibility to test the influence of non-axenic plants on unialgal or axenic cultures without the risk of contamination with other algae and the applicability for in situ studies. Either individual species or whole lake samples are put in water into dialysis bags and placed into aquaria or a lake containing the other primary producer(s) under study.

Difficulties may arise from toxic effects of some commercially available dialysis membranes, a problem solved for example by using thoroughly rinsed synthetic sausage skins (Körner \& Nicklisch, 2002). Knowledge about the potential size of the active compounds to select the appropriate pore size of dialysis membranes is also important. Even without a detailed chemical characterisation, we might expect most active compounds to be low molecular weight secondary metabolites $(<1000 \mathrm{Da})$.

To control for shading effects, controls receive plastic plants or other shades such as perforated metal plates or nylon stockings. Alternatively, target specimens can be kept just below the water surface to minimise shading (Jasser, 1995). Further problems might arise from using plastic plants, which might not be an inert control since they can exude plasticisers or other potential toxic compounds.

In a controlled laboratory experiment using aquaria, the allelopathic effect of submerged macrophytes on different phytoplankton species kept in dialysis bags was investigated (Körner \& Nicklisch, 2002). PAM fluorometry revealed that M. spicatum and C. demersum but not Potamogeton pectinatus interfered with PS II activity of four cyanobacteria, a diatom and a green alga in a species-specific manner. M. spicatum also inhibited the growth of certain target species. Recently, in situ dialysis bag experiments in a small lake with a dense stand of $M$. verticillatum revealed seasonal and species-specific allelopathic effects on different phytoplankton species (Hilt et al., 2006). Laboratory experiments, performed in parallel to this field study, investigating allelopathic interactions both under phosphorus limited and non-limiting conditions showed that phosphorus limitation might mask potential allelopathic effects for some of the target species. Two other studies investigating allelopathic interactions between submerged macrophytes and phytoplankton pinned down nutrient effects. Synechococcus leopoliensis growth was enhanced in the presence of Elodea canadensis in a smallscale coexistence study, and inhibitory effects of allelochemicals from Stratiotes aloides declined when target species were nutrient limited (potassium or phosphorus limitation; Mulderij et al., 2007).

\section{Culture filtrates}

Frequently, culture filtrates of macrophytes cultivated in aquaria or mesocosms, or even water from dense stands in the field, have been added to monospecific algal or cyanobacterial cultures (e.g., Kogan \& Chinnova, 1972; Mulderij et al., 2003, 2005a, b) or to natural phytoplankton communities (Jasser, 1995; Mulderij et al., 2006). While addition to single cultures mainly investigated growth and performance of target species, changes in community composition due to differential sensitivity can be tested with lake 
phytoplankton samples. For controls, the same water or culture medium without macrophyte exudate, or water from the same lake, but outside the macrophyte stands can be used. In general, adjustment for nutrient uptake by plants is made by addition of at least the major nutrients such as phosphorus and nitrogen to the culture filtrate, which might lead to a slightly higher concentration in the treatments compared to the controls.

Exudate experiments often involve a one-time inoculum of the filtrate (e.g., Lombardo et al., unpublished), which contains high concentrations of the alleged allelochemicals under examination, to a culture of target species. Growth patterns of target species are compared with those in exudate-free controls, and if differences are observed, they are ascribed to allelochemicals. Though seemingly fail-proof, such approaches often fail to detect allelopathic effects, even if parallel coexistence experiments suggest at least a partial implication of such a mechanism (Lombardo et al., unpublished). Such shortcomings may be derived from flaws in the filtration procedure, or from loss of inhibitory effects due to adsorption to non-target surfaces or to volatility of some allelochemicals (Gross, 2003a).

At least some of these problems may be circumvented with multiple, sequential exudate additions during an experiment. This method should account also for potential microbial or photochemical degradation of active compounds. In fact, several authors (Nakai et al., 1999; Mulderij et al., 2003, 2005a, b, 2006) showed that only one initial addition of culture filtrate underestimated the allelopathic effect compared to coexistence assays or the (semi)-continuous addition of active culture filtrate.

As in other types of experiments, nutrient concentrations are rarely determined in exudate experiments. High nutrient concentrations (as often used in exudate experiments) may, however, counteract allelopathic inhibition of target species, thus potentially confounding the results. On the other hand, allelopathy experiments carried out at low nutrient levels may fail to show effects because target species may be nutrient limited in controls (Mulderij et al., 2007). As for other types of experiments, determinations of the availability of major nutrients $(\mathrm{P}, \mathrm{N})$, and possibly also micronutrients, is highly desirable in studies with exudates.

Extracting active compounds from the culture filtrate

To avoid difficulties in adjusting appropriate nutrient concentrations in treatments and controls, some authors extracted culture filtrate and control water with either organic solvents or solid phases. Previous studies showed that most active compounds are at least moderately lipophilic, thus can be extracted in e.g., diethyl ether or ethyl acetate, or can be trapped with reversed phase sorbens (e.g., C18) of SPE cartridges and filters. Such techniques have been successfully used to prove the allelopathic activity of culture filtrates from C. demersum, Elodea nuttallii, M. spicatum and N. marina (Gross et al., 1996, 2003; Erhard \& Gross, 2006). C18-coated filters prevent the fast clogging of cartridges by solid or colloidal particles. These techniques do not require large volumes of organic solvents, which may themselves act inhibitory or contain toxic impurities, and can be adjusted to extracted water volumes from a few centilitres to a few litres. C18-bound active compounds can be eluted with solvent, usually methanol or ethanol. Enrichment of culture filtrate 5,000- to 20,000-fold is possible, allowing a controlled addition of exudate to defined media without differences in nutrient concentration. Using a step-wise elution of bound compounds with increasing methanol:water ratios in SPE or fractionation of exudates by HPLC ultimately leads to the isolation of active compounds and comparison to active compounds found in extracts.

\section{Discussion}

Proving allelopathic interaction in an ecologically meaningful way is not easy. None of the currently available methods per se addresses all of Willis' (1985) pre-requisites (i.e., inhibition, production, release, transport, uptake, exclusion of other factors; see introduction) to prove allelopathy. Some methods, such as extracts experiments, may 
provide strong evidence for some but not all of those requisites (e.g., allelopathy production vs. transport/uptake). Others (e.g., coexistence experiments) may address most of Willis' (1985) requirements, but none in a complete, conclusive way (Fig. 1). Also, exclusion of potential involvement of nutrients in macrophyte-phytoplankton interactions is typically more difficult to address in experiments with a higher degree of realism (Fig. 1). It is therefore important to keep in mind alternative explanations for the observed patterns and choose the right methods. The above mentioned approaches can be modified and integrated in a plethora of ways in order to reflect the complexity of the situation in situ.

Modifications of the main approaches used to study allelopathy should reflect natural physical, chemical, and biological factors as closely as possible. The following approaches could be used:

- Changes in nutrient status and light availability of both target and donor species.

- Testing a wide range of target species, including blends of allopatric and sympatric popula- tions to account for possible co-evolutionary effects.

- Investigating the seasonality of allelopathic effects. This implies also that allelopathic interference might differ depending on the physiological status of both donor and target species.

- Testing the impact of other stressors, such as the presence of herbivores and/or pathogens, on allelopathic interactions.

Space-limitations restrict a thorough discussion of all of those aspects, but we would like to focus on some important issues in more detail.

One of the main problems of in situ studies on allelopathic interactions is the interference with nutrient competition. Several authors wondered whether separating resource competition from allelopathy is at all realistic (Inderjit \& del Moral, 1997; Lürling et al., 2006; Lombardo et al., unpublished). Phosphorus and nitrogen limitation may affect the production and release of allelopathic compounds by submerged macrophytes (Gross, 2003b), as well as the response of the target organism (Reigosa et al., 1999).

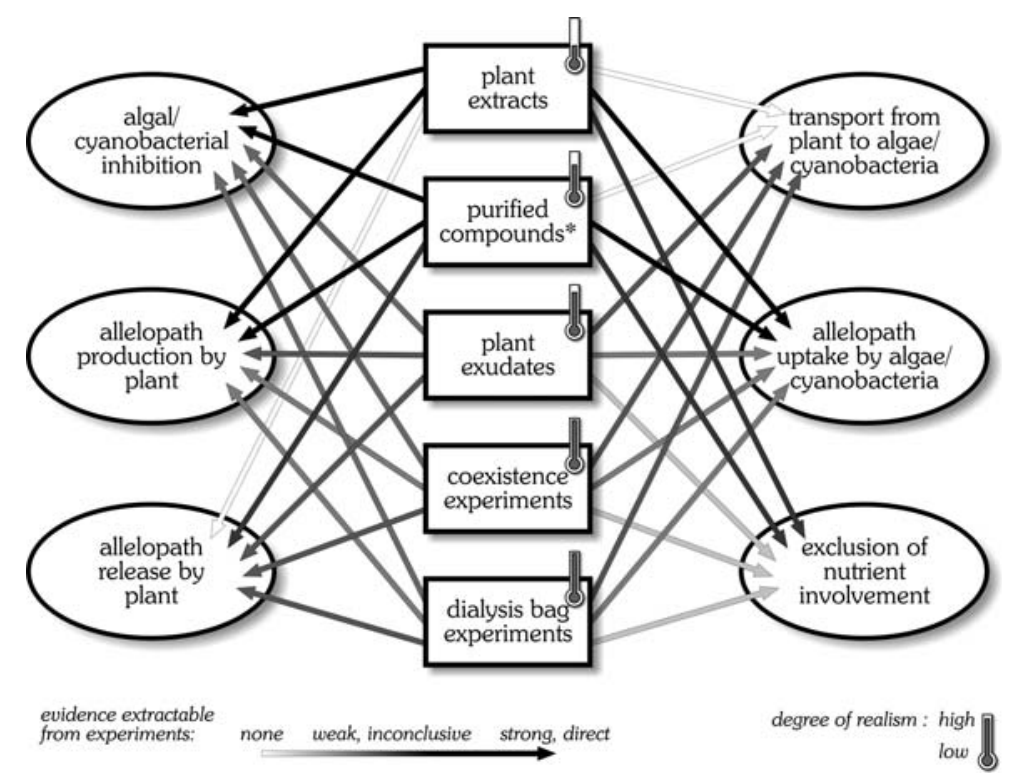

Fig. 1 Schematic representation of the evidence extractable from typical allelopathy experimental set-ups (boxes) addressing different aspects of plant-algal allelopathic interactions as requested by Willis (1985; ellipses). The sixth prerequisite, i.e., the exclusion of other factors potentially involved in plant-algae interactions, has been simplified towards nutrient involvement sensu latu, as exclusion of other factors (i.e., shading, herbivory) is easier to accomplish experimentally. The degree of realism, represented by a "thermometer", is illustrated for each experiment type. Details of the separate experimental approaches and their pros and cons can be found in the text. *purified compounds $=$ purified active compounds from extracts or exudates 
As macrophytes have the potential to reduce or increase nutrient levels in shallow lakes (van Donk \& van de Bund, 2002), competition for nutrients or an excess nutrient supply may occur. Thus, field studies will never allow discrimination between allelopathy and resource competition. Knowledge of the nutrient status of both donor and target species seems crucial for allelopathy experiments, as e.g., phosphorus limitation enhanced inhibition of alkaline phosphatase in cyanobacteria mediated by polyphenols released from M. spicatum (Gross et al., 1996), or low nitrogen availability resulted in an increased tellimagrandin II content in this macrophyte (Gross, 2003b). Phosphorus-limited Chlorella minutissima was, however, not more sensitive to Chara exudates than non-limited cultures (Mulderij et al., 2003), but Scenedesmus obliquus grown under lower light intensities was more sensitive to allelopathic substances from Stratiotes than cultures grown at high light intensities (Mulderij et al., 2005a). Lombardo et al. (unpublished) have shown that, though the relative importance of competition for nutrients and allelopathy could not be quantified, algal inhibition by coexisting plants occurred only when sprigs grew actively (i.e., during net accrual of biomass and net nutrient sequestration). This is indirectly supported by observations of higher production of secondary metabolites by aquatic plants under increased light and nutrient conditions (Cronin \& Lodge, 2003). The seemingly contradictory results of Cronin \& Lodge (2003) vs. Gross (2003b) suggest that the influence of physiological status on the production of allelochemicals may be influenced by species-specific responses to stress, nutrient status, and other environmental factors, further complicating the assessment of allelopathic effects.

Additionally, herbivory on macrophytes can influence allelopathy. Allelopathic effects may be severely dampened when tissue containing high concentrations of allelochemicals is removed (Gross et al., 2001). Thus, herbivory might also cause changes in the dominance of certain macrophytes with allelopathic activity. On the other hand, snails that do not eat living macrophytes often enhance their growth even under highnutrient conditions that would otherwise favour algae (Underwood, 1991; Brönmark \& Vermaat, 1998; McCollum et al., 1998; Lombardo \& Cooke, 2001). Thus, the assessment of herbivore influence may be very important for in situ allelopathy experiments.

The picture gets more complex as secondary metabolites with allelopathic activity may possess further biological activity, such as antiherbivore or antimicrobial effects. The hydrolysable polyphenols in $M$. spicatum comprise all those activities (Choi et al., 2002; Leu et al., 2002; Walenciak et al., 2002). The cyclic sulphur compounds considered responsible for allelopathic activity in Chara have insecticidal properties (Anthoni et al., 1982; Jacobsen \& Pedersen, 1983). In plant-herbivore and plant-pathogen interactions, defensive compounds might be constitutively present in the plant or can be induced upon feeding damage. Further, nutrient status has often been considered to influence plant content of especially carbon-based secondary metabolites sensu the 'Carbon-Nutrient Balance Hypothesis' (Bryant et al., 1983; Koricheva, 2002; Gross, $2003 \mathrm{~b}$ ). If more than one factor may affect the content of defensive compounds, we have to expect variation in allelopathic activity. Studies investigating more than two groups of organisms, e.g., concurrent herbivory (plant-animal) and allelopathy (plant-plant) experiments, are needed to find answers to these questions.

Bacteria can not only be pathogens of plants, including macrophytes, but may also contribute to the degradation of released bioactive compounds. Such effects have frequently been observed (Nakai et al., 1999; Gross, 2003a). (Sun)light might also cause chemical changes of released allelochemicals due to oxidation, polymerisation or cleavage, comparable to effects on other extracellular organic compounds (Cole, 1999). We strongly call for more studies on changes of exuded bioactive compounds caused by bacteria or light.

Coming back to prerequisite no. 4 of Willis (1985), cited in the introduction, a major problem of most studies on aquatic allelopathy is the dilution of active compounds and no clear insight into concentrations of active compounds in situ. The problem may occur at any scale, but may be particularly acute in large-scale investigations. 
Several authors have independently suggested a possible involvement of allelopathy behind observed phytoplankton patterns in whole-lake studies of vegetated, shallow lakes (Mjelde \& Faafeng, 1997; Blindow et al., 2002; Lombardo, 2005). However, none could provide any evidence in favour of or against allelopathy, and the debate on the role of allelopathy at ecosystem level remains open.

Inhibition at a close range, i.e., in macrophyteepiphyte interactions, seems much more probable, but has seldom been studied, also because of the problems associated with cultivating such organisms. Bioassays used to study such interactions would not necessarily rely on exudates and liquid cultures, but rather on 2-dimensional assays, such as agar-diffusion assays (e.g., Gross et al., 2003; Erhard \& Gross, 2006). Trials testing the impact of $M$. spicatum and $M$. verticillatum on suspended cultures of common epiphytic species (Stigeoclonium tenue, Gomphonema parvulum and Oscillatoria limosa) did not show significant effects (Hilt, 2006). Some authors suggested that allelopathic interactions are more likely between organisms from different environments because of possible adaptations of the target species towards donors (Reigosa et al., 1999). Lower inhibition or even stimulation of epiphytes isolated from donor plants such as Elodea nuttallii support this view (Erhard \& Gross, 2006).

Allelopathic inhibition between different phytoplankton species had been regarded impossible due to the vast distances between donor and target species (Lewis, 1986). Yet, active compounds might not be equally distributed in the water column, i.e., they might bind easily to surfaces because of their chemical characteristics (lipophilic compounds should bind to cell membranes easily). In terrestrial and aquatic studies, so-called micelles (Fischer \& Quijano, 1985; Perez \& Martin, 2001) have been discussed as vehicles for transport of allelopathical compounds. Again, more detailed studies are needed to address the question of release, distribution and physical range of action of allelochemicals in aquatic systems.

The explanatory power gained from the available methods (Fig. 1) depends on how much evidence is gained for each of Willis' (1985) requirements. The complex interactions strongly demand a combination of experimental approaches to maximise the experimental evidence and degree of realism.

\section{Conclusion}

Conclusive evidence for allelopathy in action in aquatic systems has eluded ecologists for years, and may continue to do so. Despite absence of a final proof in favour of (or against) allelopathy, the information gathered so far strongly suggests that allelopathy in aquatic systems indeed may be real, though it may be influenced by many factors, from environmental conditions to genetically based species-specific responses, possibly interacting synergistically and/or in non-linear ways. Our knowledge in this field has increased in recent years thanks to improvements in investigative techniques, also refined by the few answers and many questions gathered from earlier research. We believe that different pieces of evidence can be combined from multiple-approach allelopathy investigations, each targeting specific questions, eventually leading us to the answers that we seek. New developments in technology and methodology will further assist ecologists in their quest to assess the extent of allelopathy as a factor behind mutual exclusion of macrophytes and phytoplankton/epiphyton.

Acknowledgments We greatly appreciate helpful discussion with Marit Mjelde during the Shallow Lakes 2005 meeting. We very much acknowledge constructive comments by Miquel Lürling and an anonymous reviewer on a previous version of this manuscript. This project was in part supported by the German Science Foundation (DFG) in Project SFB454-A2 to EMG and by a grant by the Berliner Programm zur Förderung von Frauen in Forschung und Lehre to $\mathrm{SH}$.

\section{References}

Agami, M. \& Y. Waisel, 1985. Inter-relationship between Najas marina L. and three other species of aquatic macrophytes. Hydrobiologia 126: 169-173.

Akehurst, S. C., 1931. Observations on pond life. Journal of the Royal Microscopic Society, London 51: 236265.

Anthoni, U., C. Christophersen, N. Jacobsen \& A. Svendsen, 1982. Synthesis of 4-methylthio-1,2-dithio- 
lane and 5-methylthio-1,2,3-trithiane. Two naturally occurring bioactive compounds. Tetrahedron 38: 2425-2427.

Blindow, I., A. Hargeby \& G. Andersson, 2002. Seasonal changes of mechanisms maintaining clear water in a shallow lake with abundant Chara vegetation. Aquatic Botany 72: 315-334.

Brönmark, C. \& J. E. Vermaat, 1998. Complex fish-snailepiphyton interactions and their effects on submerged freshwater macrophytes. In Jeppesen, E., M. Søndergaard, M. Søndergaard \& K. Christoffersen (eds), The Structuring Role of Submerged Macrophytes in Lakes, Springer, New York. Ecological Studies 131: 47-68.

Bryant, J. P., F. S. Chapin III \& D. R. Klein, 1983. Carbon/ nutrient balance of boreal plants in relation to vertebrate herbivory. Oikos 40: 357-368.

Choi, C., C. Bareiss, O. Walenciak \& E. M. Gross, 2002. Impact of polyphenols on the growth of the aquatic herbivore Acentria ephemerella (Lepidoptera: Pyralidae). Journal of Chemical Ecology 28: 2223-2235.

Cole, J. J., 1999. Aquatic microbiology for ecosystem scientists: new and recycled paradigms in ecological microbiology. Ecosystems 2: 215-225.

Cronin, G. \& D. M. Lodge, 2003. Effect of light and nutrient availability on the growth, allocation, carbon/ nitrogen balance, phenolic chemistry, and resistance to herbivory of two freshwater macrophytes. Oecologia 137: 32-41.

Elakovich, S. D. \& J. W. Wooten, 1989. Allelopathic potential of 16 aquatic and wetland plants. Journal of Aquatic Plant Management 27: 78-84.

Elakovich, S. D. \& J. W. Wooten, 1995. Allelopathic, herbaceous, vascular hydrophytes. In Inderjit, K. M. M. Dakshini \& F. A. Einhellig (eds), Allelopathy-organisms, processes, and applications, ACS Symposium series 582. American Chemical Society, Washington, DC, pp 58-73.

Erhard, D. \& E. M. Gross, 2006. Allelopathic activity of Elodea canadensis and E. nuttallii against epiphytes and phytoplankton. Aquatic Botany 85: 203-211.

Ervin, G. N. \& R. G. Wetzel, 2000. Allelochemical autotoxicity in the emergent wetland macrophyte Juncus effusus (Juncaceae). American Journal of Botany 87: 853-860.

Fischer, N. H. \& L. Quijano, 1985. Allelopathic agents from common weeds. In A. C. Thompson (ed.), The Chemistry of Allelopathy, ACS Symposium Series. American Chemical Society, Washington, D.C. 268: 133-147.

Fitzgerald, G. P., 1969. Some factors in the competition or antagonism among bacteria, algae and aquatic weeds. Journal of Phycology 5: 351-359.

Forsberg, C., 1965. Nutritional studies of Chara in axenic cultures. Physiologia Plantarum 18: 275-290.

Forsberg, C., S. Kleiven \& T. Willen, 1990. Absence of allelopathic effects of Chara on phytoplankton in situ. Aquatic Botany 38: 289-294.

Gopal, B. \& U. Goel, 1993. Competition and allelopathy in aquatic plant communities. Botanical Review 59: 155210.
Gross, E. M., 1999. Allelopathy in benthic and littoral areas: Case studies on allelochemicals from benthic cyanobacteria and submersed macrophytes. In Inderjit, K. M. M. Dakshini \& C. L. Foy (eds), Principles and practices in plant ecology: allelochemical interactions. CRC Press, LLC, Boca Raton, 179-199.

Gross, E. M., 2003a. Allelopathy of aquatic autotrophs. Critical Reviews in Plant Sciences 22: 313-339.

Gross, E. M., 2003b. Differential response of tellimagrandin II and total bioactive hydrolysable tannins in an aquatic angiosperm to changes in light and nitrogen. Oikos 103: 497-504.

Gross, E. M., D. Erhard \& E. Ivanyi, 2003. Allelopathic activity of Ceratophyllum demersum L. and Najas marina ssp. intermedia. Hydrobiologia 506: 583-589.

Gross, E. M., R. L. Johnson, N. G. Hairston Jr., 2001. Experimental evidence for changes in submersed macrophyte species composition caused by the herbivore Acentria ephemerella (Lepidoptera). Oecologia 127: 105-114.

Gross, E. M., H. Meyer \& G. Schilling, 1996. Release and ecological impact of algicidal hydrolyzable polyphenols in Myriophyllum spicatum. Phytochemistry 41: 133-138.

Gurevitch, J., S. M. Scheiner \& G. A. Fox, 2002. The Ecology of Plants. Sinauer Associates Inc., Sunderland, MA, USA. See p. 193 for De-Wit replacement series.

Harder, R., 1917. Ernährungsphysiologische Untersuchungen an Cyanophyceen, hauptsächlich dem endophytischen Nostoc punctiforme. Zeitschrift für Botanik IX: $145-242$.

Hasler, A. D. \& E. Jones, 1949. Demonstration of the antagonistic action of large aquatic plants on algae and rotifers. Ecology 30: 359-364.

Hilt, S., 2006. Allelopathic inhibition of epiphytes by submerged macrophytes. Aquatic Botany 85: 252256.

Hilt, S., M. Ghobrial \& E. M. Gross, 2006. In situ allelopathic potential of Myriophyllum verticillatum (Haloragaceae) against selected phytoplankton species. Journal of Phycology: 42:1189-1198.

Inderjit \& R. del Moral, 1997. Is separating resource competition from allelopathy realistic? Botanical Review 63: 221-230.

Jacobsen, N. \& L. E. K. Pedersen, 1983. Synthesis and insecticidal properties of derivatives of propane-1,3dithiol (analogs of the insecticidal derivatives of dithiolane and trithiane from the alga Chara globularis (Thuillier). Pesticide Science 14: 90-97.

Jasser, I., 1995. The influence of macrophytes on a phytoplankton community in experimental conditions. Hydrobiologia 306: 21-32.

Keating, K. I., 1977. Allelopathic influence on blue-green bloom sequence in a eutrophic lake. Science 196: 885887.

Kogan, S. I. \& G. A. Chinnova, 1972. Relations between Ceratophyllum demersum (L.) and some blue-green algae. Hydrobiological Journal (Ghidrobiol. Zh.) 8: 14-19 (21-27). 
Koricheva, J., 2002. The Carbon-Nutrient Balance Hypothesis is dead: long live the Carbon-Nutrient Balance Hypothesis? Oikos 98: 537-539.

Körner, S. \& A. Nicklisch, 2002. Allelopathic growth inhibition of selected phytoplankton species by submerged macrophytes. Journal of Phycology 38: 862871.

Leu, E., A. Krieger-Liszkay, C. Goussias, E. M. Gross, 2002. Polyphenolic allelochemicals from the aquatic angiosperm Myriophyllum spicatum L. inhibit photosystem II. Plant Physiology 130: 2011-2018.

Lewis, W. M. Jr., 1986. Evolutionary interpretation of allelochemical interactions in phytoplanktonic algae. American Naturalist 127: 184-194.

Lombardo, P. \& G. D. Cooke, 2001. Effects of freshwater gastropods on epiphyton, macrophytes, and water transparency under meso- to eutrophic conditions. Chapter from PhD Dissertation. Kent State University, Kent, OH, USA.

Lombardo, P. \& G. D. Cooke, 2003. Ceratophyllum demersum: phosphorus interactions in nutrient enriched aquaria. Hydrobiologia 497: 79-90.

Lombardo, P., 2005. Applicability of littoral food-web biomanipulation for lake management purposes: snails: macrophytes, and water transparency in northeast Ohio shallow lakes. Lake and Reservoir Management 21: 186-202.

Lürling, M., G. van Geest \& M. Scheffer, 2006. Importance of nutrient competition and allelopathic effects in suppression of the green alga Scenedesmus obliquus by the macrophytes Chara, Elodea and Myriophyllum. Hydrobiologia 556: 209-220.

McCollum, E. W., L. B. Crowder \& S. A. McCollum, 1998. Complex interactions of fish, snails, and littoral zone periphyton. Ecology 79: 1980-1994.

Mjelde, M. \& B. A. Faafeng, 1997. Ceratophyllum demersum hampers phytoplankton development in some small Norwegian lakes over a wide range of phosphorus concentrations and geographical latitude. Freshwater Biology 37: 355-365.

Molisch, H., 1937. Der Einfluss einer Pflanze auf die andere-Allelopathie. Fischer, Jena.

Mulderij, G., B. Mau, E. van Donk \& E. M. Gross, 2007. Allelopathic activity of Stratiotes aloides on phytoplankton-towards identification of allelopathic substances. Hydrobiologia 584: 89-100.

Mulderij, G., W. M. Mooij, A. J. P. Smolders \& E. van Donk, 2005a. Inhibition of phytoplankton by allelopathic substances from Stratiotes aloides. Aquatic Botany 82: 284-296.

Mulderij, G., W. M. Mooij \& E. van Donk, 2005b. Allelopathic growth inhibition and colony formation of the green alga Scenedesmus obliquus by the aquatic macrophyte Stratiotes aloides. Aquatic Ecology 39: 11-21.

Mulderij, G., A. J. P. Smolders \& E. van Donk, 2006. The allelopathic effect of Stratiotes aloides on phytoplankton under natural conditions. Freshwater Biology 51: 554-562.

Mulderij, G., E. van Donk \& J. G. M. Roelofs, 2003. Differential sensitivity of green algae to allelopath- ic substances from Chara. Hydrobiologia 491: 261-271.

Nakai, S., Y. Inoue, M. Hosomi \& A. Murakami, 1999. Growth inhibition of blue-green algae by allelopathic effects of macrophytes. Water Science \& Technology 39: 47-53.

Pelton, D. K., S. N. Levine \& M. Braner, 1998. Measurements of phosphorus uptake by macrophytes and epiphytes from the LaPlatte River (VT) using ${ }^{32} \mathrm{P}$ in stream microcosms. Freshwater Biology 39: 285-299.

Perez, E. \& D. F. Martin, 2001. Critical micelle concentrations of allelopathic substances produced by Nannochloris oculata which affect a red tide organism, Gymnodinium breve. Cytobios 106: 163-170.

Phillips, G. L., D. Eminson, \& B. Moss, 1978. A mechanism to account for macrophyte decline in progressively eutrophicated freshwaters. Aquatic Botany 4: 103-126.

Pratt, R., R. C. Daniels, J. J. Eiler, J. B. Gunnison, W. D. Kumler, J. F. Oneto, L. A. Strait, H. A. Spoehr, G. J. Hardin, H. W. Milner, J. H. C. Smith \& H. H. Strain, 1944. Chlorellin, an antibacterial substance from Chlorella. Science 99: 351-352.

Pringsheim, E. G. \& O. Pringsheim, 1962. Axenic culture of Utricularia. American Journal of Botany 49: 898901.

Reigosa, M. J., A. Sanchez-Moreiras \& L. Gonzalez, 1999. Ecophysiological approach in allelopathy. Critical Reviews in Plant Sciences 18: 577-608.

Scheffer, M., S. H. Hosper, M. L. Meijer, B. Moss \& E. Jeppesen, 1993. Alternative equilibria in shallow lakes. Trends in Ecology and Evolution 8: 275-279.

Søndergaard, M., 1981. Kinetics of extracellular release of ${ }^{14} \mathrm{C}$-labelled organic carbon by submersed macrophytes. Oikos 36: 331-347.

Sukenik, A., R. Eshkol, A. Livne, O. Hadas, M. Rom, D. Tchernov, A. Vardi \& A. Kaplan, 2002. Inhibition of growth and photosynthesis of the dinoflagellate $P e$ ridinium gatunense by Microcystis sp. (cyanobacteria): a novel allelopathic mechanism. Limnology and Oceanography 47: 1656-1663.

Underwood, G. J. C., 1991. Growth enhancement of the macrophyte Ceratophyllum demersum in the presence of the snail Planorbis planorbis: the effect of grazing and chemical conditioning. Freshwater Biology 26: 325-334.

van, Donk E. \& W. J. van de Bund, 2002. Impact of submerged macrophytes including charophytes on phyto- and zooplankton communities: allelopathy versus other mechanisms. Aquatic Botany 72: 261274.

Vance, H. D. \& D. A. Francko, 1997. Allelopathic potential of Nelumbo lutea (Willd.) Pers. to alter growth of Myriophyllum spicatum L. and Potamogeton pectinatus L. Journal of Freshwater Ecology 12: 405-409.

Walenciak, O., W. Zwisler, E. M. Gross, 2002. Influence of Myriophyllum spicatum-derived tannins on gut microbiota of its herbivore Acentria ephemerella. Journal of Chemical Ecology 28: 2045-2056. 
Wetzel, R. G. \& D. L. McGregor, 1968. Axenic culture and nutritional studies of aquatic macrophytes. American Midland Naturalist 80: 52-64.

Wetzel R. G., 2001. Limnology-Lake and River Ecosystems, 3rd ed. Academic Press, San Diego, 1006 pp.

Willis, R. J., 1985. The historical bases of the concept of allelopathy. Journal of the History of Biology 18: 71-102.
Wooten, J. W. \& S. D. Elakovich, 1991. Comparisons of potential allelopathy of seven freshwater species of spikerushes (Eleocharis). Journal of Aquatic Plant Management 29: 12-15. 